\title{
Correction to: Handbook of Advanced Performability Engineering
}

\author{
Krishna B. Misra
}

\section{Correction to:}

K. B. Misra (ed.),

\section{Handbook of Advanced Performability Engineering, https://doi.org/10.1007/978-3-030-55732-4}

The original version of this book was inadvertently published with incorrect notations in Chapters 7 and 33. This has now been corrected. The book and the chapters have been updated with the changes.

The updated version of these chapters can be found at https://doi.org/10.1007/978-3-030-55732-4_7

https://doi.org/10.1007/978-3-030-55732-4_33

K. B. Misra $(\varangle)$

RAMS Consultants, Jaipur, Rajasthan, India 